NASA/TM-2002-211699

\title{
Probabilistic Analysis of Gas Turbine Field Performance
}

\author{
Rama S.R. Gorla
}

Cleveland State University, Cleveland, Ohio

Shantaram S. Pai and Jeffrey J. Rusick

Glenn Research Center, Cleveland, Ohio 
Since its founding, NASA has been dedicated to the advancement of aeronautics and space science. The NASA Scientific and Technical Information (STI) Program Office plays a key part in helping NASA maintain this important role.

The NASA STI Program Office is operated by Langley Research Center, the Lead Center for NASA's scientific and technical information. The NASA STI Program Office provides access to the NASA STI Database, the largest collection of aeronautical and space science STI in the world. The Program Office is also NASA's institutional mechanism for disseminating the results of its research and development activities. These results are published by NASA in the NASA STI Report Series, which includes the following report types:

- $\quad$ TECHNICAL PUBLICATION. Reports of completed research or a major significant phase of research that present the results of NASA programs and include extensive data or theoretical analysis. Includes compilations of significant scientific and technical data and information deemed to be of continuing reference value. NASA's counterpart of peerreviewed formal professional papers but has less stringent limitations on manuscript length and extent of graphic presentations.

- TECHNICAL MEMORANDUM. Scientific and technical findings that are preliminary or of specialized interest, e.g., quick release reports, working papers, and bibliographies that contain minimal annotation. Does not contain extensive analysis.

- CONTRACTOR REPORT. Scientific and technical findings by NASA-sponsored contractors and grantees.
- CONFERENCE PUBLICATION. Collected papers from scientific and technical conferences, symposia, seminars, or other meetings sponsored or cosponsored by NASA.

- SPECIAL PUBLICATION. Scientific, technical, or historical information from NASA programs, projects, and missions, often concerned with subjects having substantial public interest.

- TECHNICAL TRANSLATION. Englishlanguage translations of foreign scientific and technical material pertinent to NASA's mission.

Specialized services that complement the STI Program Office's diverse offerings include creating custom thesauri, building customized databases, organizing and publishing research results ... even providing videos.

For more information about the NASA STI Program Office, see the following:

- Access the NASA STI Program Home Page at http://www.sti.nasa.gov

- E-mail your question via the Internet to help@sti.nasa.gov

- Fax your question to the NASA Access Help Desk at 301-621-0134

- Telephone the NASA Access Help Desk at 301-621-0390

- Write to:

NASA Access Help Desk

NASA Center for AeroSpace Information 7121 Standard Drive

Hanover, MD 21076 
NASA/TM-2002-211699

TED-AJ03-649

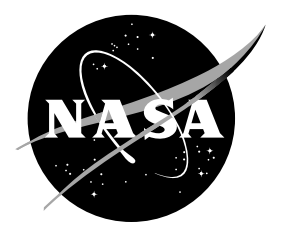

\title{
Probabilistic Analysis of Gas Turbine Field Performance
}

\author{
Rama S.R. Gorla \\ Cleveland State University, Cleveland, Ohio \\ Shantaram S. Pai and Jeffrey J. Rusick \\ Glenn Research Center, Cleveland, Ohio
}

Prepared for the

Sixth Thermal Engineering Joint Conference

cosponsored by the Japan Society of Mechanical Engineers, Thermal Engineering Division, and the American Society of Mechanical Engineers, Heat Transfer Division

Hawaii Island, Hawaii, March 16-20, 2003

National Aeronautics and

Space Administration

Glenn Research Center 


\section{Acknowledgments}

Rama S.R. Gorla is grateful to NASA Glenn Research Center, for supporting this work through Grant NAG3-2745.

This report is a preprint of a paper intended for presentation at a conference. Because of changes that may be made before formal publication, this preprint is made available with the understanding that it will not be cited or reproduced without the permission of the author.

Available from

NASA Center for Aerospace Information 7121 Standard Drive

Hanover, MD 21076
National Technical Information Service 5285 Port Royal Road Springfield, VA 22100

Available electronically at http:/ / gltrs.grc.nasa.gov 


\title{
PROBABILISTIC ANALYSIS OF GAS TURBINE FIELD PERFORMANCE
}

\author{
Rama S.R. Gorla* \\ Professor of Mechanical Engineering \\ Cleveland State University \\ Cleveland, Ohio 44115, USA
}

\author{
Shantaram S. Pai* and Jeffrey Rusick \\ National Aeronautics and Space Administration \\ Glenn Research Center \\ Cleveland, Ohio 44135, USA
}

\begin{abstract}
A gas turbine thermodynamic cycle was computationally simulated and probabilistically evaluated in view of the several uncertainties in the performance parameters, which are indices of gas turbine health. Cumulative distribution functions and sensitivity factors were computed for the overall thermal efficiency and net specific power output due to the thermodynamic random variables. These results can be used to quickly identify the most critical design variables in order to optimize the design, enhance performance, increase system availability and make it cost effective. The analysis leads to the selection of the appropriate measurements to be used in the gas turbine health determination and to the identification of both the most critical measurements and parameters. Probabilistic analysis aims at unifying and improving the control and health monitoring of gas turbine aero-engines by increasing the quality and quantity of information available about the engine's health and performance.

Conventional engineering design methods are deterministic. The components of a machine are considered as ideal systems and parameter optimizations provide single point estimates of the system response. In reality, many engineering systems are stochastic where a probability assessment of the results is required. Probabilistic engineering design analysis assumes probability distributions of design parameters, instead of mean values only. This enables the designer to design for a specific reliability and hence maximize safety, quality and cost. The approaches for incorporating probabilistic effects in design include the use of factors of safety, the use of the worst case design and the use of probabilistic design. Utilizing the

uncertainties in the estimations, deterministic engineering design uses factors of safety to assure that the nominal operational condition does not come too close to the point where the system will fail. The approximation of minimum properties and maximum loads known as the absolute worst case gives information about this critical point. This approach limits the optimization capability of a system and fails to provide important information about the system lifetime.

The design procedures of the advanced aerospace vehicles must account for uncertainties calculating the risk or reliability. These calculations will involve probabilistic analysis. When compared with traditional factor of safety methods, probabilistic methods require additional inputs but provide higher quality outputs. The uncertain or random variables are assumed to have a probability density function. The output will be a probability density function for the response quantities.

A robust design is one that has been created with a system of design tools that reduce product or process variability while guiding the performance toward an optimal setting. Robustness means achieving excellent performance under a wide range of operating conditions. All engineering systems function reasonably well under ideal conditions, but robust designs continue to function well when the conditions are non-ideal. Analytical robust design attempts to determine the values of design parameters which maximize the reliability of the product without tightening the material or environmental tolerances. Probabilistic design and robust design go hand in hand. In order to determine the domains of stability, the system has to be analyzed probabilistically.
\end{abstract}

*ASME Member. 


\section{INTRODUCTION}

Gas turbine aero-engines are used in all the new commercial aircraft and most business aircraft. Due to their capital cost and numbers installed, notably in the fleets of aircraft operated by the armed services and commercial airlines, there is considerable pressure to reduce the cost of ownership incurred by the operator. In the civil sector, this pressure is currently increasing with the rising popularity of the concept of "power by the hour" engine sales contract in which the operator is sold a fleet of engines but no spares. The operator pays the engine supplier a predetermined engine-operating rate for maintenance. Both owner and supplier share a common interest in minimizing repair and overhaul cost. Effective engine health monitoring techniques can reduce the cost of ownership by setting appropriate levels of routine maintenance and by locating and assessing the significance of specific problems with an engine. The emphasis in the gas turbine engine industry today is reduced cost in procurement and operation. Any unscheduled maintenance or outages will cause additional costs and lost revenues. In many critical applications, standby gas turbines are used for emergency conditions, thus resulting in a more cost intensive operation. The optimum use of machine availability, management and maintenance can reduce financial losses due to gas turbine outages. Madej et al. [1] discussed the monitoring of service delivery system and diagnostics of gas turbine engines. An updated schedule of gas turbine operating state will be required to diagnose the causes of performance degradation.

The gas path analysis can be used to determine the gas turbine operating state. This method uses field measurements to estimate the characteristic performance parameters by means of thermodynamic cycle analysis [2-5]. Measurements are taken of pressures and temperatures at various stations along the gas flow paths, together with other engine parameters such as the spool speeds. These measurements are used in conjunction with physical laws and the known characteristics of the engine's components such as the efficiencies of turbines and compressors. The determination of the operating state using this approach may include uncertainties in the accuracy of thermodynamic measurements and a priori selection of the geometric and performance characteristic parameters. The main benefit of such schemes to the owner/operator would be that any sudden deterioration in the engine's health parameters could be flagged almost immediately and corrective action taken before significant financial loss was incurred.

With the increase in gas turbine engine complexity and performance over the past 50 years, structural engineers have created an array of safety nets to ensure against component failures in turbine engines. In order to reduce what is now considered to be excessive conservatism and yet maintain the same adequate margins of safety, there is a pressing need to explore methods of incorporating probabilistic design procedures into engine development.
Probabilistic methods combine and prioritize the statistical distributions of each design variable, generate an interactive distribution and offer the designer a quantified relationship between robustness, endurance and performance.

Conventional engineering design methods are deterministic. Machines and their components are considered as ideal systems and parameter optimizations provide single point estimates of the system behavior or response. Probabilistic engineering design uses probability distributions of design parameters instead of mean or nominal values only. This will enable a designer for a specific reliability and hence maximize safety, quality and economy. A probabilistic design system was developed by Fox [6] at Pratt \& Whitney for the purpose of integrating deterministic design methods with probabilistic design techniques. Here, two different approaches were used for estimating uncertainty. A Monte Carlo approach was used on design codes that were judged to run relatively quickly. For more computationally intensive design codes, a second order response surface model in conjunction with Box-Behnken design experiments was used and then a Monte Carlo simulation was executed. Several researchers at NASA Glenn Research Center have applied the probabilistic design approaches to turbine engines and related systems. Chamis [7] developed a Probabilistic Structural Analysis Method (PSAM) using different distributions such as the Weibull, normal, log-normal, etc. to describe the uncertainties in the structural and load parameters or primitive variables. Nagpal, Rubinstein and Chamis [8] presented a probabilistic study of turbopump blades of the Space Shuttle Main Engine (SSME). They found that random variations or uncertainties in geometry have statistically significant influence on the response variable and random variations in material properties have statistically insignificant effects. Chamis [9] summarized the usefulness and importance of the probabilistic approach, especially for turbopumps. Gorla et al. [10] computationally simulated and probabilistically evaluated a combustor liner in view of several uncertainties in the aerodynamic, structural, material and thermal variables that govern the combustor liner.

To cost effectively accomplish the design task, we need to formally quantify the effect of uncertainties (variables) in the design. Probabilistic design is one effective method to formally quantify the effect of uncertainties. In the present paper, a probabilistic analysis is presented for the influence of measurement accuracy and a priori fixed parameter variations on the random variables for gas turbine system health determination.

\section{PROBABILITY THEORY}

Let $X_{1}, X_{2}, \ldots, X_{n}$ be a set of random variables defined on a (discrete) probability space $\Omega$. The probability that the events $X_{1}=x_{1} X_{1}, X_{2}=x_{2}, \ldots$, and $X_{n}=X_{n}$ happen concurrently, is denoted by

$f\left(x_{1}, x_{2}, \ldots, x_{n}\right)=P\left(X_{1}=x_{1}, X_{2}=x_{2}, \ldots ., X_{n}=x_{n}\right)$ for the set of desired solutions $A \subseteq \Omega$. If the function 
$f\left(x_{1}, x_{2}, \ldots, x_{n}\right)$ is discrete, it is called the joint probability mass function of $X_{1}, X_{2}, \ldots, X_{n}$ and has the following properties.

$$
\begin{aligned}
& 0 \leq f\left(x_{1}, x_{2}, \ldots, x_{n}\right) \leq 1 \\
& \sum_{\left(x_{1}, x_{2}, \ldots, x_{n}\right) \in \Omega} \sum_{f} f\left(x_{1}, x_{2}, \ldots, x_{n}\right)=1
\end{aligned}
$$

$$
\begin{aligned}
P\left[\left(X_{1}, X_{2}, \ldots, X_{n}\right) \in A\right] & =\sum_{\left(x_{1}, x_{2}, \ldots, x_{n}\right) \in \Omega} \sum_{n} f\left(x_{1}, x_{2}, \ldots, x_{n}\right)=1, A \subseteq \Omega
\end{aligned}
$$

If $f\left(x_{1}, x_{2}, \ldots, x_{n}\right)$ is continuous it is called joint probability density function of $X_{1}, X_{2}, \ldots, X_{n}$ and has the following properties:

$$
\begin{gathered}
0 \leq f\left(x_{1}, x_{2}, \ldots, x_{n}\right) \\
\int_{\Omega} \ldots \int_{1} f\left(x_{1}, x_{2}, \ldots, x_{n}\right) d x_{1} d x_{2} \ldots d x_{n}=1 \\
P\left[\left(X_{1}, X_{2}, . ., X_{n}\right) \in A\right] \\
=\int_{A} . . \int f\left(x_{1}, x_{2}, \ldots, x_{n}\right) d x_{1} d x_{2} \ldots d x_{n}, A \subseteq \Omega
\end{gathered}
$$

If the lower bound of $A$, the set of desired solutions, is equal to the infimum of $\Omega$ for all $X_{i}$, i.e., if $A=\left[\inf _{i}(\Omega)\right.$, $a_{i}$ ], for all $i=1,2, \ldots, n$, a function $F\left(a_{1}, a_{2}, \ldots, a_{n}\right)$ can be defined, such that:

$$
\begin{aligned}
& F\left(a_{1}, a_{2}, \ldots, a_{n}\right)=P\left[\left(X_{1}, X_{2}, \ldots, X_{n}\right) \in A\right] \\
& =\sum_{\left(x_{1}, x_{2}, \ldots, x_{n}\right) \in A} \ldots \sum_{1} f\left(x_{1}, x_{2}, \ldots, x_{n}\right), \\
& A \subseteq \Omega(f \text { is discrete })
\end{aligned}
$$

$$
\begin{aligned}
& F\left(a_{1}, a_{2}, \ldots, a_{n}\right)=P\left[\left(X_{1}, X_{2}, . ., X_{n}\right) \in A\right] \\
& =\int_{A} . . \int f\left(x_{1}, x_{2}, \ldots, x_{n}\right) d x_{1} d x_{2} \ldots d x_{n}, A \subseteq \Omega
\end{aligned}
$$

( $f$ is continuous)

$F$ is called the joint cumulative probability distribution function. For $\Omega=R^{n}$ and a continuous function $f$ :

$$
\begin{aligned}
& F\left(a_{1}, a_{2}, \ldots, a_{n}\right)=P\left[\left(X_{1}, X_{2}, \ldots, X_{n}\right) \in((-\infty,-\infty, \ldots,-\infty),\right. \\
& \left.\left.\left(a_{1}, a_{2}, \ldots, a_{n}\right)\right)\right]=\int_{-\infty}^{a_{n}} . . \int_{-\infty}^{a_{1}} f\left(x_{1}, x_{2}, \ldots, x_{n}\right) d x_{1} d x_{2} . . d x_{n}
\end{aligned}
$$

The common notation $F\left(a_{1}, a_{2}, \ldots, a_{n}\right)$ $=P\left(X_{1} \leq a_{1}, X_{2} \leq a_{2}, \ldots, X_{n} \leq a_{n}\right)$ will be used subsequently also.

The univariate probability function $f_{X_{i}}$ for each criterion $X_{i}$, obtained from the traditional probabilistic design process, can also be generated with the joint probability function $f . f_{x i}$ is called marginal probability mass or density function of $X_{i}$ and is defined by:

$$
\begin{aligned}
& f x_{1}=\sum_{\left(x_{2}, \ldots, x_{n}\right)} \ldots \sum_{\in R} f\left(x_{2}, \ldots, x_{n}\right) \quad(f \text { is discrete }) \\
& f x_{1}=\int_{R} \ldots \int f\left(x_{2}, \ldots, x_{n}\right) d x_{2} \ldots d x_{n}(f \text { is continuous })
\end{aligned}
$$

The joint probability function, $f_{X Y}(x, y)$, creates the surface of a probability 'hump' in the $x-y-f$-space, characterized by rings of constant probabilities. The distribution curves over the $x$ - and $y$-axis are the aforementioned marginal probability functions $f_{X}(x)$ and $f y(y)$, respectively. The last necessary concept to mention here for the development of a joint probabilistic formulation is the concept dependence of criteria. Two random variables $X$ and $Y$ are said to be independent, if $f_{X Y}(x, y)=f_{X}(x) . f_{Y}(y)$ otherwise $X$ and $Y$ are said to be dependent. This dependence is a mathematical notion and should not be confused with 'casual dependence'. For here on, mathematical dependence will be referred to as correlation. Correlation is measured by the covariance of two criteria, $X$ and $Y$, defined by

$$
\operatorname{Cov}(X, Y)=E[X, Y]-E[X] E[Y]
$$

It is more convenient, however, to use a covariance normalized by the standard deviations, $\sigma_{X}$ and $\sigma_{Y}$, for both criteria, called correlation coefficient.

$$
\rho=\frac{\operatorname{Cov}(X, Y)}{\sigma X \sigma Y}
$$

The correlation coefficient is defined over the interval $[-1,1]$, indicating strongly positively correlated criteria at values close to 1 and strongly negatively correlated criteria at values close to -1 . The criteria are independent, if $\rho=0$. In aerospace systems design $\rho$ can be quite difficult to calculate by Eq. (9). It is much more effective to view the correlation coefficient differently for calculation purposes. Jointly collected data from a probabilistic or any other analysis can be thought of as vectors of numbers. The correlation coefficient measures the orthogonality, i.e., independence, of both vectors. $\rho$ is simply the cosine of the angle between the two criterion vectors, indicating their alignment. For $\rho=1$, vectors are parallel and point in same direction, for $\rho=-1$, vectors are parallel and point in opposite direction. For $\rho=0$, vectors are 
orthogonal and the criteria are independent. The correlation coefficient plays a significant role in the formulation of joint probability distribution models as described in the next section.

\section{Probability Functions}

Attention is now directed to the implementation of this probabilistic formulation in the design process. The necessary transition from the mathematical formulation above to a probabilistic model that yields the information relevant for multi-variate decision making is described in this section. There are two alternatives for this task.

\section{Joint Probability Model}

The first joint probability density function introduced here is an analytical probability model for criteria whose univariate distributions and their corresponding means and standard deviations are known. All necessary information for the model can be generated by the traditional probabilistic design process, using its output of univariate criterion distributions. A particular model for two criteria with normal distributions, represented by Eq. (10), has been introduced by Garvey and Tuab. Garvey further generated models for two criteria with combinations of normal and lognormal distributions, which are summarized in Ref. [11].

$$
\begin{aligned}
f_{X Y}(x, y)= & \frac{1}{2 \pi \sigma X \sigma \sqrt{1-\rho^{2}}} \exp \left\{\frac { 1 } { 2 \rho ^ { 2 } - 2 } \left[\left(\frac{x-\mu x}{\sigma X}\right)^{2}\right.\right. \\
& \left.\left.-2 \rho\left(\frac{x-\mu X}{\sigma X}\right)\left(\frac{y-\mu Y}{\sigma Y}\right)+\left(\frac{y-\mu Y}{\sigma Y}\right)^{2}\right]\right\}
\end{aligned}
$$

Note that the only information needed for the Joint Probability Model consists of the means $\mu_{X}$ and $\mu_{Y}$, the standard deviations $\sigma_{X}$ and $\sigma_{Y}$, and the correlation coefficient $\rho$ for the criteria $X$ and $Y$. The model variables, $x$ and $y$, are defined over the interval of all possible criterion values. The advantage of this model is the limited information needed, which makes it very flexible for use and application. For example, if only expert knowledge and no simulation/modeling is available in the early stages of design, educated guesses for the means, standard deviations, and the correlation coefficient can be used to execute the joint probability model. It also lends itself to use in combination with increasingly important fast probability integration (FPI) techniques.

\section{Implementation of Probabilistic Procedure Using FPI}

FPI is a probabilistic analysis tool that implements a variety of methods for probabilistic analysis. The procedure follows the steps given below:

1. Identify the independent and uncorrelated design variables with uncertainties.
2. Quantify the uncertainties of these design variables with probability distributions based on expert opinion elicitation, historical data or benchmark testing.

3. It is required that there is a response function that defines the relationship between the response and the independent variables.

4. The FPI uses the responses generated to compute the cumulative distribution functions (CDF)/ probability density functions (PDF) and the corresponding sensitivities of the response.

Several methods are available in the FPI to compute a probabilistic distribution. In addition to obtaining the $\mathrm{CDF} / \mathrm{PDF}$ of the response, the FPI provides additional information regarding the sensitivity of the response with respect to the primitive variables. They provide valuable information in controlling the scatter of the response variable. The random primitive variable with the highest sensitivity factor will yield the biggest payoff in controlling the scatter in that particular response variable. Such information is very useful to the test/design engineer in designing or interpreting the measured data.

\section{DISCUSSION OF RESULTS}

The probabilistic analysis of gas turbine field performance due to the uncertainties was applied to a $10 \mathrm{MW}$ two shaft heavy duty industrial gas turbine with variable power turbine nozzle. Figure 1 shows the layout of the gas turbine system. The thermodynamic random variables and their respective values used in this analysis are shown in Table 1 . The random variables are labeled in Table 2. All the random variables were assumed to be independent. A scatter of $\pm 10 \%$ was specified for all the variables. Normal distribution was assumed for all random variable scatters.

The overall thermal efficiency of the gas turbine system was determined from a control volume analysis using the first and second laws of thermodynamics. The cumulative distribution functions (CDF) and the sensitivity factors were evaluated for the overall thermal efficiency response. CDF for the overall thermal efficiency are

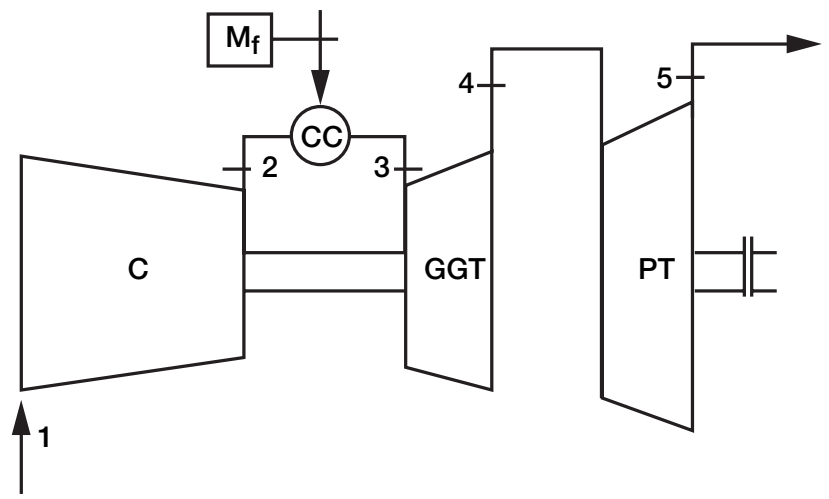

Figure 1 Layout of the gas turbine system. 
Table 1.-Random Variables

\begin{tabular}{|l|l|}
\hline \multicolumn{1}{|c|}{ Random Variable } & \multicolumn{1}{|c|}{$\begin{array}{c}\text { Mean } \\
\text { Value }\end{array}$} \\
\hline Compressor inlet pressure (P1) & $101.3 \mathrm{kPa}$ \\
\hline Compressor inlet temperature (T1) & $288 \mathrm{~K}$ \\
\hline Compressor exit (P2) & $1439.9 \mathrm{kPa}$ \\
\hline Mass flow rate of fuel (M) & $0.645 \mathrm{~kg} / \mathrm{s}$ \\
\hline Compressor turbine (CGT) exit pressure (P4) & $306.0 \mathrm{kPa}$ \\
\hline Adiabatic efficiency of compressor & 0.85 \\
\hline Adiabatic efficiency of compressor turbine & 0.90 \\
\hline Adiabatic efficiency of power turbine & 0.86 \\
\hline
\end{tabular}

Table 2.-Random Variable Labels

\begin{tabular}{|l|l|}
\hline \multicolumn{1}{|c|}{ Label } & \multicolumn{1}{c|}{ Description } \\
\hline P1 & Compressor inlet pressure \\
\hline T1 & Compressor inlet temperature \\
\hline P2 & Compressor exit \\
\hline T3 & Inlet temperature to the compressor turbine \\
\hline P4 & Compressor turbine (CGT) exit pressure \\
\hline COMPEFF & Adiabatic efficiency of compressor \\
\hline TURB1EFF & Adiabatic efficiency of compressor turbine \\
\hline TURB2EFF & Adiabatic efficiency of power turbine \\
\hline
\end{tabular}

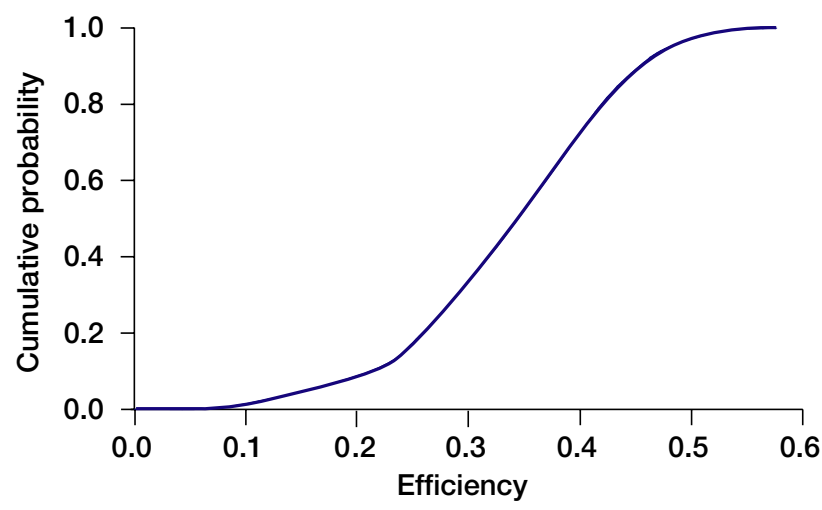

Figure 2 Cumulative probability of overall thermal efficiency.

shown in Fig. 2. The sensitivity factors for the overall thermal efficiency are plotted in Figs. 3-5. From these figures, we observe that the inlet pressure and temperature of the compressor, exit pressure of the compressor, inlet temperature to the compressor gas turbine and adiabatic efficiencies of the compressor turbine and power turbine have a lot of influence on the overall thermal efficiency. These thermodynamic random variables represent the most important indices for the gas turbine health determination. The adiabatic efficiencies of the compressor and turbines in the system are measures of irreversibilities or increase of entropy. The sensitivity factor for the compressor adiabatic efficiency is much smaller than those for the compressor turbine and power turbine. The sensitivity factors due to the adiabatic efficiencies of the compressor turbine and power turbine influence the most in the determination of the overall thermal efficiency of the system.

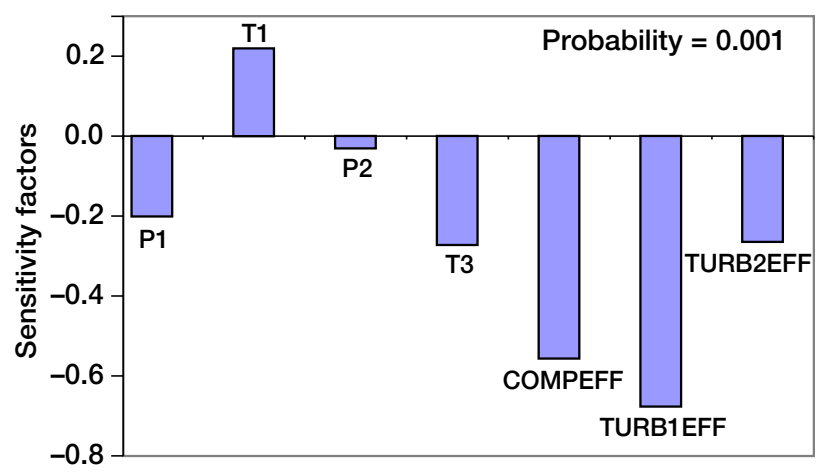

Random variables

Figure 3 Sensitivity factors versus random variables.

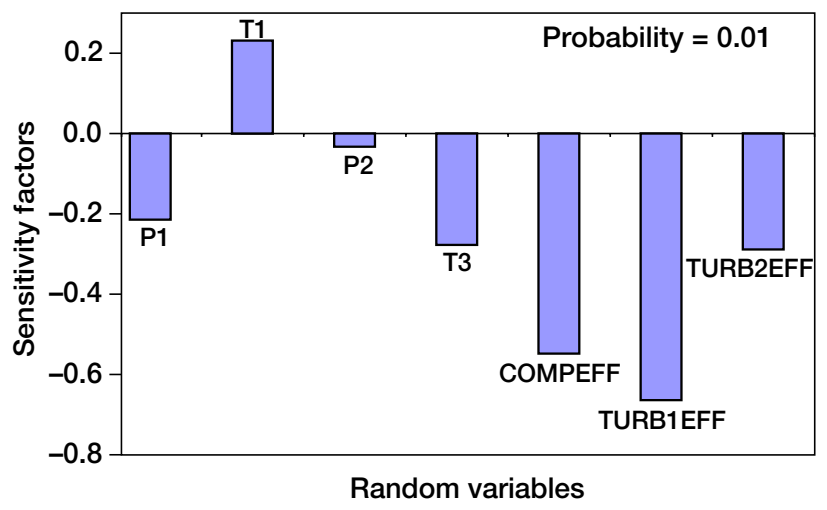

Figure 4 Sensitivity factors versus random variables.

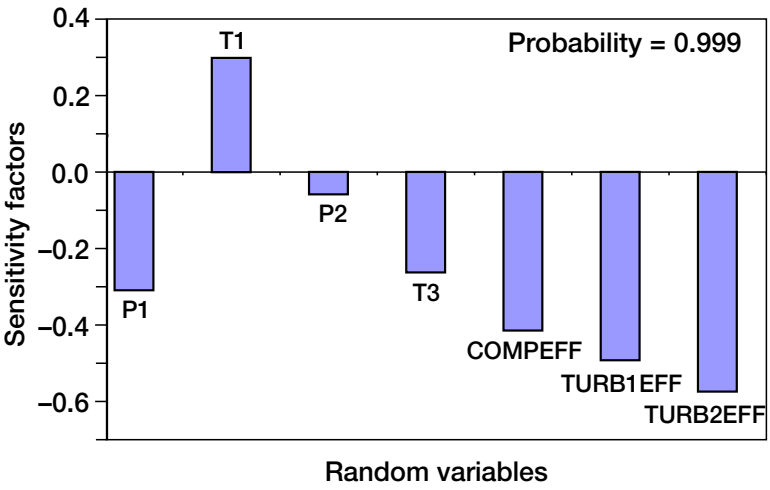

Figure 5 Sensitivity factors versus random variables.

Figure 6 shows the CDF for the net specific output of the gas turbine system. The sensitivity factors for the net specific output are plotted in Figs. 7-9. The sensitivity factor due to the compressor turbine inlet temperature influences the most in the evaluation of the net specific power output in the cycle.

These results can be used to further optimize the design for cost effectiveness and also to assist in the health determination of the system. The prediction of degradation of system performance can be achieved from the results obtained. 


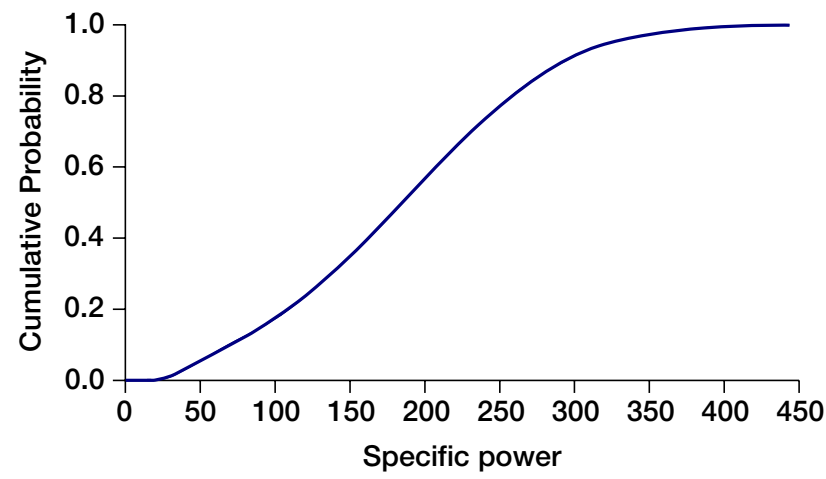

Figure 6 Cumulative probability of net specific power output.

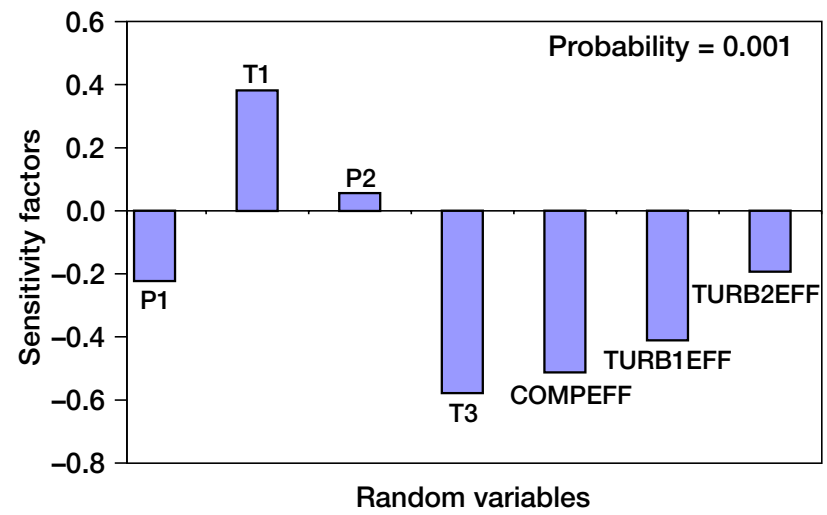

Figure 7 Sensitivity factors versus random variables.

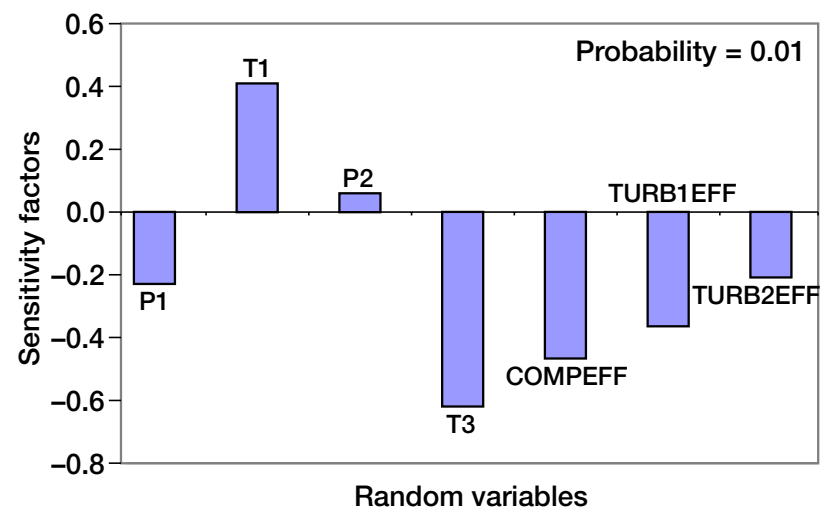

Figure 8 Sensitivity factors versus random variables.

\section{CONCLUDING REMARKS}

In this paper, a non-deterministic, non-traditional method has been developed to support reliability-based aerospace design. The revolutionary part of the proposed work is the probabilistic evaluation of the thermodynamic analysis. The nontraditional part of the proposed work is the identification of criteria for using computational accuracy. Probabilistic methods were applied to the

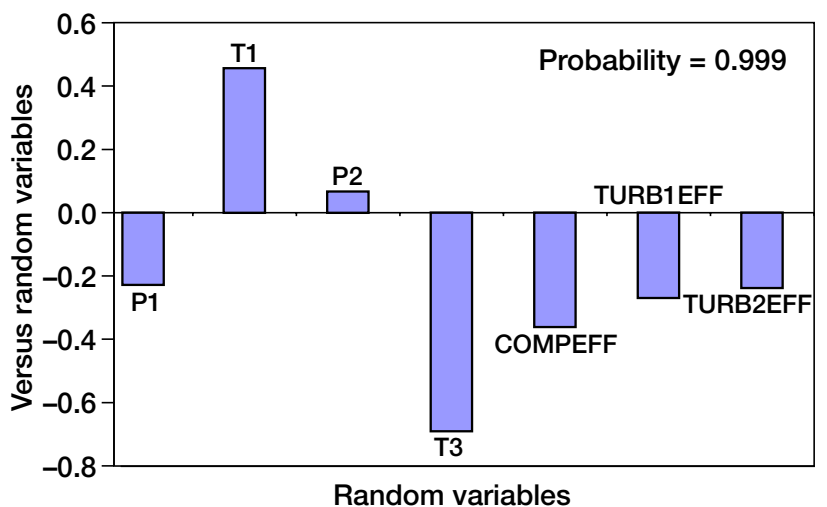

Figure 9 Sensitivity factors versus random variables.

thermodynamic analysis of a gas turbine system. The interconnection between the thermodynamic analysis and NESTEM codes was necessary to compute the probabilistic evaluation of a gas turbine field performance. Overall thermal efficiency and net specific power output of the gas turbine plant was evaluated using the thermodynamic random variables. Cumulative distribution functions and sensitivity factors were computed for the overall thermal efficiency and net specific power output due to the thermodynamic random variables. Evaluating probability of risk and sensitivity factors will enable the identification of the most critical design variables in order to optimize the design, make it cost effective and assist in the health determination of the system.

\section{REFERENCES}

[1] Madej, J., Longtin K., and Smith, D.P., 1996, "Monitoring Service Delivery System and Diagnostics," Proceedings, $39^{\text {th }}$ GE Turbine State-of-the-Art Technology Seminar, General Electric Company, Schenectady, New York, GER-3956.

[2] Stamatis, A., Mathioudakis, K., and Papailiou, K.D., 1990, "Adaptive Simulation of Gas Turbine Performance," ASME J. Eng. Gas Turbine Power, 112, pp. $168-175$.

[3] Doel, D.L., 1994, "TEMPER-A Gas-Path Analysis Tool for Commercial Jet Engines," ASME J. Eng. Gas Turbines Power, 116, pp. 82-89.

[4] Doel, D.L., 1994, "An Assessment of WeightedLeast-Squares based Gas Path Analysis," ASME J. Eng. Gas Turbine Power, 116, pp. 366-373.

[5] Pinelle, M., and Spina, P.R., 2002, "Gas Turbine Field Performance Determination: Sources of Uncertainties," 124, pp. 155-160.

[6] Fox, E.P., 1994, "The Pratt \& Whitney Probabilistic Design System," AIAA-94-1442-CP.

[7] Chamis, C.C., 1986, "Probabilistic Structural Analysis Methods for Space Components," Space Systems Technology Conference, San Diego, California, June 9-12, 1986. 
[8] Nagpal, V.K., Rubinstein, R., and Chamis, C.C., 1987," Probabilistic Structural Analysis to Quantify Uncertainties Associated with Turbopump Blades," AIAA-87-0766.

[9] Chamis, C.C., 1986, "Probabilistic Structural Analysis Methods for Critical SSME Propulsion Components," Third Space Systems Technology Conference, AIAA, pp. 133-144.
[10] Gorla, R.S.R., Pai, S.S., and Rusick, J.J., 2002, "Probabilistic Study of Fluid Structure Interaction," International Journal of Engineering Science (in print).

[11] Sundararajan, R., 1995, "Probabilistic Structural Mechanics Handbook," Chapman and Hall, New York, NewYork. 


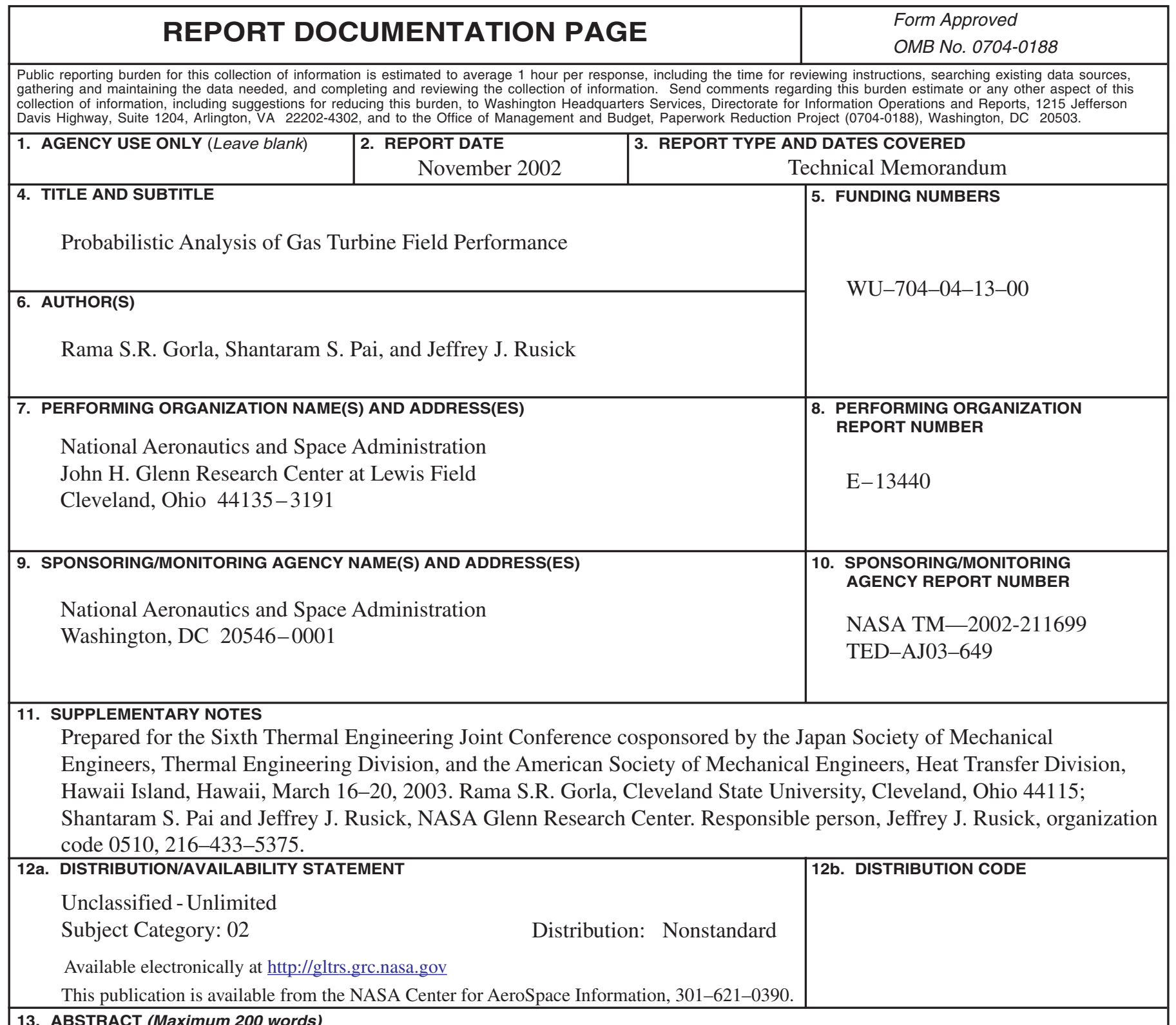

\section{ABSTRACT (Maximum 200 words)}

A gas turbine thermodynamic cycle was computationally simulated and probabilistically evaluated in view of the several uncertainties in the performance parameters, which are indices of gas turbine health. Cumulative distribution functions and sensitivity factors were computed for the overall thermal efficiency and net specific power output due to the thermodynamic random variables. These results can be used to quickly identify the most critical design variables in order to optimize the design, enhance performance, increase system availability and make it cost effective. The analysis leads to the selection of the appropriate measurements to be used in the gas turbine health determination and to the identification of both the most critical measurements and parameters. Probabilistic analysis aims at unifying and improving the control and health monitoring of gas turbine aero-engines by increasing the quality and quantity of information available about the engine's health and performance.

\section{SUBJECT TERMS}

Thermodynamic cycle; Probabilistic analysis; Gas turbines; Health monitoring 15. NUMBER OF PAGES

\begin{tabular}{|c|c|c|}
\hline $\begin{array}{c}\text { 17. SECURITY CLASSIFICATION } \\
\text { OF REPORT } \\
\text { Unclassified }\end{array}$ & $\begin{array}{c}\text { 18. SECURITY CLASSIFICATION } \\
\text { OF THIS PAGE } \\
\text { Unclassified }\end{array}$ & $\begin{array}{c}\text { 19. SECURITY CLASSIFICATION } \\
\text { OF ABSTRACT } \\
\text { Unclassified }\end{array}$ \\
\hline
\end{tabular}

